\title{
Effect of Palm Tocotrienols versus Alpha- Tocopherol on Lymphocyte's Proliferation in Streptozotocin-Induced Diabetic Rats
}

\author{
Mansooreh Sadat Mojani ${ }^{1}$, Vahid Hosseinpour Sarmadi ${ }^{2}$, \\ Asmah Rahmat ${ }^{1}$ and Rajesh Ramasamy ${ }^{2}$ \\ ${ }^{1}$ Department of Nutrition and Dietetics, Faculty of Medicine and Health Sciences, Universiti Putra \\ Malaysia, Malaysia \\ ${ }^{2}$ Immunology Unit, Department of Pathology, Faculty of Medicine and Health Sciences, Universiti \\ Putra Malaysia, Malaysia
}

Correspondence should be addressed to: Rajesh Ramasamy; r.rajesh@medic.upm.edu.my

Received 17 April 2013; Accepted 2 May 2013; Published 18 June 2013

Academic Editor: HawWen Chen

Copyright $\odot 2013$ Mansooreh Sadat Mojani, Vahid Hosseinpour Sarmadi, Asmah Rahmat and Rajesh Ramasamy. Distributed under Creative Commons CC-BY 3.0

\begin{abstract}
In this study, the effect of palm oil based vitamin E was evaluated on lymphocyte`s proliferation in streptozotocin-induced diabetic rats. Diabetic rats were supplemented with alphatocopherol (AT) and/or mixed-tocotrienols (TT) at two dosages 6 and 12mg/kg for 8 weeks. Treated rats were sacrificed and their spleens isolated for lymphocyte proliferation assay in response to two mitogens namely lipopolysaccharide (LPS) and phytohemagglutinin (PHA). Our results indicated that in the resting state, the lymphocytes of untreated diabetic rats had a marked increase in cell proliferation compared with the treated rats; however, upon stimulation with PHA or LPS, the untreated diabetic lymphocytes failed to respond. Lymphocytes from animals treated with AT $(12 \mathrm{mg} / \mathrm{kg})$ alone and the combination of two supplements (AT and TT for $6 \mathrm{mg} / \mathrm{kg}$ ) showed a significant proliferation when challenged with mitogens where the particular supplementations ameliorate lymphocyte impairment by reconstituting the cellular proliferation in diabetic rats. This study suggested that the supplementation of AT alone at higher concentration or combination with TT even at lower doses can restore the lymphocyte proliferation which is an important phase in immune cell responses.
\end{abstract}

Keywords: Palm vitamin E; alpha-tocopherol; tocotrienols; lymphocyte.

\section{Introduction}

Altering the immune response due to hyperglycemia has been recognized as the key factor that leads to the development of diseases linked to diabetes mellitus
(Rubinstein et al., 2008). Diabetes predisposes the patient to serious infection. Many clinical studies support the association between diabetes and infection, but the mechanisms associating diabetes and immunosuppression are not perfectly

Cite this Article as: Mansooreh Sadat Mojani, Vahid Hosseinpour Sarmadi, Asmah Rahmat and Rajesh Ramasamy (2013), "Effect of Palm Tocotrienols versus Alpha-Tocopherol on Lymphocyte's Proliferation in Streptozotocin-Induced Diabetic Rats," Research in Immunology: An International Journal, Vol. 2013 (2013), Article ID 189211, DOI: 10.5171/2013.189211 
clear (Pickup, 2004). It has been hypothesized that hyperglycemia induced by diabetes might be a potential mediator of immunosuppression (Peleg et al., 2007, Skyler, 2011, Van Belle et al., 2011). In line with this, experimentally-induced diabetic mice exhibited altered humoral immune responses which directly affect the $\mathrm{T}$ lymphocyte reactivity by reducing the $\mathrm{T}$ cell proliferation (Rubinstein et al., 2008).

Vitamin E is closely associated with maintaining the integrity of normal physiology and the immune system. Several animal and human studies indicated that supplementation of this vitamin (especially $\alpha$-tocopherol) could improve the immune responses (Beharka et al., 1997, Meydani et al., 1997, Moriguchi et al., 1990). It was shown that vitamin E increased lymphocyte proliferation in aged mice (Beharka et al., 1997, Meydani et al., 1986, Ren et al., 2010). Almost all the studies on the effect of vitamin $E$ supplementation on the immune system have used $\alpha$-tocopherol or other tocopherol homologues (Dayong et al., 2000, Pae et al., 2012), and little information is available for the immunological effect of other forms of vitamin E, especially tocotrienols. Due to consumption of palm products, people in South East Asia may have higher intake of tocotrienols compared with the rest of the world. Thus, it is important to investigate some of the immunologic effects of mixedtocotrienols and compare them with a standard $\alpha$-tocopherol on lymphocytesmediated function, which were the objectives of the present study.

\section{Materials and Methods}

\section{Animals}

The animal study approval was obtained from Animal Care and Use Committee (ACUC) of the Faculty of Medicine and Health Sciences, Universiti Putra Malaysia. Male Albino white rats from SpragueDawley species were supplied by the A Sapphire Enterprise, Selangor, Malaysia. Forty eight rats with average body weight of $235 \mathrm{~g}$ were used in this study; animals were housed in animal cages at animal house at $25 \pm 3 \stackrel{\circ}{\circ} \mathrm{C}$ temperature, $50-60 \%$ humidity, and a $12 \mathrm{~h}$ light-dark cycle. They were maintained on a regular commercial diet (Gold Coin, Malaysia) (14\% fat, 61\% carbohydrate, and $25 \%$ protein from total energy) and ad libitum water.

\section{Experimental Design}

Rats were randomly divided into 8 groups: (i) Normal control rats given basal diet, (ii) Diabetic control rats given basal diet; (iii) AT $6 \mathrm{mg} / \mathrm{kg}$ : Diabetic rats treated with $\alpha$ tocopherol $6 \mathrm{mg} / \mathrm{kg}$; (iv) AT $12 \mathrm{mg} / \mathrm{kg}$ : Diabetic rats treated with $\alpha$-tocopherol 12 $\mathrm{mg} / \mathrm{kg}$ (v) TT $6 \mathrm{mg} / \mathrm{kg}$ : Diabetic rats treated with mixed-tocotrienols $6 \mathrm{mg} / \mathrm{kg}$; (vi) TT $12 \mathrm{mg} / \mathrm{kg}$ : Diabetic rats treated with mixed-tocotrienols $12 \mathrm{mg} / \mathrm{kg}$; (vii) AT+TT $6 \mathrm{mg} / \mathrm{kg}$ : Diabetic rats treated with both $\alpha$-tocopherol and mixed-tocotrienols $6 \mathrm{mg} / \mathrm{kg}$ from each supplement, and (viii) AT+TT $12 \mathrm{mg} / \mathrm{kg}$ : Diabetic rats treated with both $\alpha$-tocopherol and mixed-tocotrienols $12 \mathrm{mg} / \mathrm{kg}$. Each group consists of six rats. Diabetic rats were induced diabetes using freshly prepared streptozotocin [55 mg/kg body weight dissolved in citrate buffer $(\mathrm{PH}=4.5)]$. Alpha-tocopherol (pure natural $\alpha$-tocopherol) (Carotech Berhad, Malaysia) and mixed-tocotrienol known as Tocomin 80\% (55.6\% d-gamma tocotrienols, 5.5\% d-beta tocotrienol, $14.2 \% \quad$ d-delta tocotrienol and 9.5\% d-alpha tocotrienol) (Carotech Berhad, Malaysia) were given daily by oral gavage using feeding needles.

Vitamin E-free corn oil (0.2 ml) (Acros Organics, Fairlawn, NJ, USA) was used as the vehicle; corn oil was selected because of its minimum effect on the immune system (Calder, 1998). Supplementation started in fully induced diabetic rats (fasting blood glucose $>11.1 \mathrm{mmol} / \mathrm{L}$ ) and continued for 8 weeks. Body weights of rats and fasting blood glucose were measured throughout the study.

\section{Proliferation Assay}

Following 8 weeks of treatment, spleens were harvested from sacrificed rats and splenocytes were isolated using a 
previously described standard procedure (Millar et al., 1993). One hundred single spleen cell suspensions in $100 \mu \mathrm{l}$ media were dispersed in 96-well round bottom plates with the concentration of $1 \times 10^{6}$ cells $/ \mathrm{ml}$ and cultured in the presence and absence of mitogen. The mitogens used in this study were lipopolysaccharide (LPS) $(5 \alpha \mathrm{g} / \mathrm{ml})$ and phytohemagglutinin (PHA) $(5 \alpha \mathrm{g} / \mathrm{ml})$ in triplicate. The assays were incubated for 2 hours with $0.5 \alpha \mathrm{Ci}$ of ${ }^{3} \mathrm{H}$ thymidine added at final 18 hours of the assay. After incubation, the cells were harvested and radioactivity was measured using the luminescent Microbeta counter (Wallac). Results were expressed as counts per minute (CPM).

\section{Statistical Methods}

Results are stated as the mean \pm standard error. Mean differences were ascertained with one-way analysis of variance (ANOVA) followed by the LSD Post Hoc test to compare each treatment group with the control group. Pearson product-moment correlation coefficient is used to find any relationship between the variables of mitogenic responses and blood glucose level, $p<0.05$ was considered significant.

\section{Results}

\section{Vitamin $E$ Normalized Lymphocyte Proliferation after Stimulation}

In order to provide information related to the general immunologic ability of AT and TT and evaluate cell-mediated immunity in diabetic condition, lymphocyte proliferation assay was used. PHA and LPS mitogens were selected since both are general mitogens for $\mathrm{T}$ cell proliferation whereby LPS stimulation is mediated by $\mathrm{B}$ cells and PHA stimulates T cells as superantigen. Based on this assay (Figure 1), in the resting condition, un-stimulated lymphocytes showed a significant rise in proliferation rate in the diabetic control compared with the normal control (4291 \pm 172 vs. $1264 \pm 327$ ); surprisingly, after supplementation. 
(A)

(B)

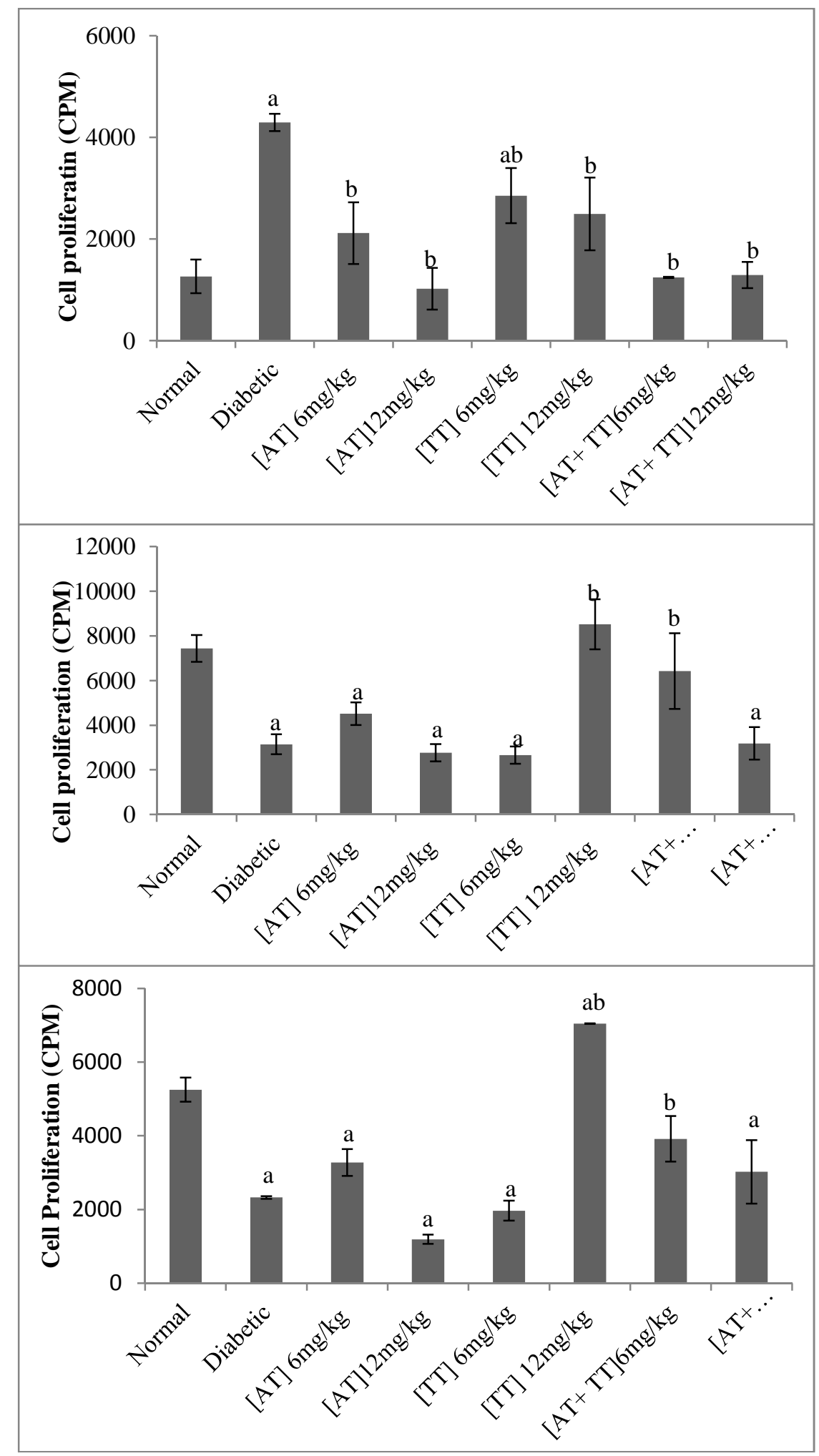

Figure 1. Assessment of Splenocyte Proliferation. (A) No Stimulated Cells (B) PHA Stimulation (C) LPS Stimulation 
Splenocytes from $\alpha$-tocopherol and mixedtocotrienols treated rats were cultured with PHA and LPS. At the end of incubation, the proliferation of cells determined by ${ }^{3} \mathrm{H}-$ thymidine assay. Results have been shown as mean with the standard errors. a: significantly different from normal control group, b: significantly different from diabetic control group and ab: significantly different from both normal and diabetic control group $(p<0.05)$. Data are presented as counts per minute (CPM). Normal: Normal Control, Control: Diabetic Control, AT: alpha-tocopherol, TT: mixedtocotrienols.

With vitamin E, the diabetic lymphocytes became less active and their proliferation levels were back to normal. The mean score for the diabetic control group was significantly different $(\mathrm{p}<0.05)$ from all treated groups. However, after stimulation with PHA, a significant difference was observed in $\mathrm{T}$ cells among experimental groups. Despite reaching statistical significance $(\mathrm{p}<0.05)$, the actual mean differences between the groups were quite small among all groups. Only the mean of

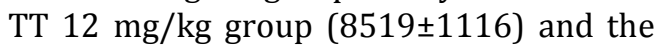
combination of both AT and TT for $6 \mathrm{mg} / \mathrm{kg}$ group (6423 \pm 1698$)$ were considerably different from the diabetic control group (3146 \pm 451$)$. After stimulation with LPS, a significant difference was observed among the eight groups $(\mathrm{p}<0.05)$. Similar to PHA, the mean score for the diabetic control group (2329 \pm 37$)$ was significantly lower than that of the normal control $(5250 \pm 32)$, and TT $12 \mathrm{mg} / \mathrm{kg}(7041 \pm 8)$ and the combination of both AT and TT for $6 \mathrm{mg} / \mathrm{kg}$ $(3918 \pm 615)$ groups were significantly different from the diabetic control group.

\section{Blood Glucose was Negatively Correlated with Proliferation}

Levels of fasting blood glucose were measured on the last day of treatment. All diabetic rats had significantly higher level of blood glucose compared with normal rats. Although blood glucose level did not significantly decreased following treatment with vitamin E; yet TT $12 \mathrm{mg} / \mathrm{kg}$ and both combination group showed some regulatory effects $(p>0.05)$ (Table 1$)$.The correlation between mitogenic responses of spleen cells and fasting blood glucose level (Table 2) showed no significant relationship between the proliferation of unstimulated cells and LPS-stimulated cells with blood glucose. Statistically, the only significant correlation was observed between PHA-stimulation and blood glucose level. The correlation between blood glucose and proliferation was negative; high levels of blood glucose showed lower proliferation of lymphocytes. But this association with PHA stimulation looks greater (medium level of correlation) than the other conditions.

Table 1. Mean Value of Blood Glucose Level in Experimental Groups

\begin{tabular}{|l|l|l|l|l|l|l|l|l|}
\hline & Normal & Diabetic & AT 6 mg/kg & $\begin{array}{l}\text { AT } \mathbf{~ 1 2} \\
\mathbf{m g} / \mathbf{k g}\end{array}$ & $\begin{array}{l}\text { TT } \\
\mathbf{m g} / \mathbf{k g}\end{array}$ & $\begin{array}{l}\text { TT } \\
\mathbf{m g} / \mathbf{k g}\end{array}$ & $\begin{array}{l}\text { AT+TT 6 } \\
\mathbf{m g} / \mathbf{k g}\end{array}$ & $\begin{array}{l}\text { AT+TT } \\
\mathbf{1 2} \\
\mathbf{m g} / \mathbf{k g}\end{array}$ \\
\hline $\begin{array}{l}\text { Fasting blood } \\
\text { glucose(mmol/L) }\end{array}$ & $4.23 \pm 0.08$ & $18.9 \pm 1^{\mathrm{a}}$ & $27.5 \pm 4.9 \mathrm{a}$ & $26.1 \pm 3.7^{\mathrm{a}}$ & $23.8 \pm 0.9^{\mathrm{a}}$ & $20.1 \pm 2.7^{\mathrm{a}}$ & $20.1 \pm 2.7^{\mathrm{a}}$ & $18.4 \pm 0.3^{\mathrm{a}}$ \\
\hline
\end{tabular}

a: Means are significantly different from the normal control group ( $\mathrm{p}<0.05)$, by analysis of variance (One-way ANOVA) $(n=6)$, no significant decline were observed in the treated group compared with the diabetic control group. Even, AT 6 $\mathrm{mg} / \mathrm{kg}$ showed significantly higher blood glucose compared to diabetic control (b) at $\mathrm{p}<0.05$. 
Table 2. Relationship between Reactivity of T Cells in Different Stimulation Conditions and Blood Glucose Level

\begin{tabular}{|l|l|l|l|l|}
\hline & & $\begin{array}{l}\text { Unstimulated } \\
\text { cells }\end{array}$ & $\begin{array}{l}\text { PHA stimulated } \\
\text { T cells }\end{array}$ & $\begin{array}{l}\text { LPS stimulated } \\
\text { T cells }\end{array}$ \\
\hline $\begin{array}{l}\text { Fasting blood } \\
\text { glucose } \\
\text { (mmol/L) }\end{array}$ & $\begin{array}{l}\text { Correlation } \\
\text { P value }\end{array}$ & -0.035 & $-0.426^{\mathrm{a}}$ & -0.325 \\
& 0.86 & 0.027 & 0.098 \\
\\
a: values are significantly correlated (p<0.05) , byPearson product-moment correlation coefficient (n=6).
\end{tabular}

\section{Discussion}

Diabetes mellitus is a complex disorder with unknown etiology (Wright et al., 2006). Oxidative stress (Pradhan et al., 2001) and inflammation(Duncan and Schmidt, 2001) have been proposed as the major causes in the development of insulin resistance, $\alpha$-cell dysfunction, impaired glucose tolerance and type 2 diabetes mellitus. Inflammation itself is linked with increasing levels of some proinflammatory cytokines such as tumor necrosis factor- $\alpha$ (TNF- $\alpha$ ), interleukin 6 (IL-6) and Creactive protein (CRP) (Pradhan et al., 2001). Accordingly, it is proposed that activation of the innate immune system well correlates with the onset and development of type 2 diabetes (Duncan and Schmidt, 2001). Alpha-tocopherol has been broadly studied and well known for its useful effect in human immune systems (Garcia-Bailo et al., 2011, Meydani, 1995, Meydani and Beharka, 1998, Reiter et al., 2007). It is a lipid-soluble antioxidant in plasma and LDL with anti-inflammatory properties (Singh et al., 2005). It has proved to be beneficial for patients suffering from cardiovascular diseases (Kaul et al., 2001).

Our results indicate that lymphocytes from untreated diabetic rats in resting state had a significant rise in proliferation rate compared to a normal control, and following stimulation with mitogens, they could not proliferate well. This indicates the inability of the diabetic cells responses to stimulators that may have been due to the low sensitivity of T cells; furthermore, the effect of prolonged chronic inflammation of cells after induction of diabetes might have suppressed lymphocyte`s activation. After supplementation with $\alpha$-tocopherol and mixed-tocotrienols, the proliferation rates of diabetic lymphoctes increased; these results are in agreement with a previous study which has shown that dietary supplementation with $\alpha$-tocopherol could enhance the mitogenic response of splenocytes to concanavalin A (Con A)-and LPS in old mice(Meydani et al., 1986). Moreover, vitamin E (dl- $\alpha$-tocopheryl acetate) has been observed to improve mitogen-stimulated lymphocyte proliferation in healthy elderly subjects (Meydani et al., 1990). Reportedly, palm oil tocotrienol-rich fraction (TRF) was also able to improve quantitative measures of chronic pancreatic damage in a rat model (González et al., 2011), and $\alpha$-tocotrienol (GT) was more effective in suppressing Con A-induced $\mathrm{T}$ cell proliferation than AT (Wilankar et al., 2011). Our study elucidated both the mixture tocotrienols alone in higher dosage and combining with $\alpha$-tochopherol even at lower dose had the capability to enhance lymphocyte proliferation.

We also demonstrated that the blood glucose is not considerably changed in test groups with vitamin E supplementation, this effect was well established by other works (Boshtam et al., 2005, Sena et al., 2008). But, the correlation between blood glucose level and the proliferation index of lymohocytes in response to both stimuli indicates that the capacity of diabetic lymphocytes to proliferate against bacterial mitogens reduced gradually. This imposes a threat to diabetic patients where they may predispose to bacterial infections and delay wound healing that might lead to diabetic complications such as gangrene. 
However, the current study only had utilized the general mitogens that nonspecifically stimulate $\mathrm{T}$ cells. In such circumstances, antigen specific stimulation toward peptides needs to be carried out whether diabetes affects the immune integrity of such stimulation. However, this only delineates the fact that diabetic lymphocytes were compromised in term of their proliferation capacity.

Vitamin E exerts modulator effects on both inflammatory and immune components of the immune system due to its antioxidant behavior. Lack of vitamin $\mathrm{E}$ and low tissue content develop components of the inflammatory responses (Singh and Jialal, 2004). Our finding suggests that the mechanism of vitamin $\mathrm{E}$ is related to its direct effect on proliferation of lymphocytes independent from hypoglycemic effects, since our results didn't indicate any positive impact on blood glucose; $\alpha$-tocopherol and tocotrienol mixture are able to enhance lymphocyte`s proliferation by increasing cell-dividing ability in response to mitogen. Moreover, our pervious finding(Mojani et al., 2012)demonstrated that palm based vitamin $E$ decreased the amount of serum IL- 6 and TNF- $\alpha$ in the same group of treated rats that may be challenged with $\mathrm{T}$ cell function; future studies are recommended to clarify the possible effects. Although our data revealed some benefits of palm tocotrienols and $\alpha$ tocopherol on lymphocytes of diabetic rats, but our results should be interpreted with caution regarding immune cell function. Additional functional assays may be needed to highlight the advantages of palm oil on the immune system.

In summary, our study suggests that supplementation of $\alpha$-tocopherol and mixed-tocotrienols can restore the diabetic lymphocyte`s proliferative function and serve as prophylaxis for diabetes associated infection and disorders. TT was even more potent and could recompense the ability of low doses of $\alpha \alpha$ in the enhancement of lymphocyte`s proliferation. Supplementation of TT with a higher dose increased splenocyte proliferation for PHA and LPS stimulation; these results propose benefits of TT when fed in high doses and combination of AT and TT on the immune system.

\section{Acknowledgement}

The authors would like to thank all the staff from the Nutrition, Immunology, and Pathology labs and Animal House of the faculty of Medicine and Heath Sciences, Universiti Putra Malaysia. They are also grateful to Carotech Berhad, Malaysia, for kindly providing the supplements.

\section{References}

Beharka, A. A., Wu, D., Han, S. N. \& Meydani, S. N. (1997). "Macrophage Prostaglandin Production Contributes to the AgeAssociated Decrease in $\mathrm{T}$ Cell Function Which is Reversed by the Dietary Antioxidant Vitamin E," Mechanisms of Ageing and Development, 93, 59-77.

Boshtam, M., Rafiei, M. \& Sarraf-Zadegan, N. (2005). "Long-Term Effect of Oral Vitamin E Supplement on Type II Diabetic Patients," International Journal for Vitamin and Nutrition Research, 75, 346-347.

Calder, P. C. (1998). "Immunoregulatory and Anti-Inflammatory Effects of N-3 Polyunsaturated Fatty Acids," Brazilian Journal of Medical and Biological Research, 31, 467-490.

Dayong, W. U., Meydani, M., Beharka, A. A., Serafini, M., Martin, K. R. \& Meydani, S. N. (2000). "In Vitro Supplementation with Different Tocopherol Homologues Can Affect the Function of Immune Cells in Old Mice," Free Radical Biology and Medicine, $28,643-651$.

Duncan, B. B. \& Schmidt, M. I. (2001). "Chronic Activation of the Innate Immune System May Underlie the Metabolic Syndrome," São Paulo Medical Journal, 119, 122-127.

Garcia-Bailo, B., El-Sohemy, A., Haddad, P. S., Arora, P., Benzaied, F., Karmali, M. \& Badaw, A. (2011). "Vitamins D, C, and E in the Prevention of Type 2 Diabetes Mellitus: 
Modulation of Inflammation and Oxidative Stress," Biologics: Targets \& Therapy5, 719.

Gonzalez, A. M., Garcia, T., Samper, E., Riickmann, M., Vaquero, E. C. \& Molero, X. (2011). "Assessment of the Protective Effects of Oral Tocotrienols in Arginine Chronic-Like Pancreatitis," American Journal of Physiology - Gastrointestinal and Liver Physiology, 301, G846-G855.

Kaul, N., Devaraj, S. \& Jialal, I. (2001). "Alpha-Tocopherol and Atherosclerosis," Experimental Biology and Medicine, 226, 5-32.

Meydani, M. (1995). “Vitamin E," Lancet 345, 170-175.

Meydani, S. N. \& Beharka, A. A. (1998). "Recent Developments in Vitamin E and Immune Response," Nutrition Reviews56, S49-S58.

Meydani, S. N., Barklund, M. P., Liu, S., Meydani, M., Miller, R. A., Cannon, J. G., Morrow, F. D., Rocklin, R. \& Blumberg, J. B. (1990). "Vitamin E Supplementation Enhances Cell-Mediated Immunity in Healthy Elderly Subjects," American Journal of Clinical Nutrition, 52, 557-563.

Meydani, S. N., Meydani, M., Blumberg, J. B., Leka, L. S., Siber, G. \& Loszewski, R. (1997). "Vitamin E Supplementation and in Vivo Immune Response in Healthy Elderly Subjects. A Randomized Controlled Trial," JAMA, 227, 1380-1386.

Meydani, S. N., Meydani, M., Verdon, C. P., Shapiro, A. C., Blumberg, J. B. \& Hayes, K. C. (1986). "Vitamin E Supplementation Suppresses Prostaglandin E2 Synthesis and Enhances the Immune Response of Aged Mice," Mech. Ageing Dev 34, 191-201.

Millar, D. B., Thomas, J. R., Pacheco, N. D. \& Rollwagen, F. M. (1993). "Natural Killer Cell Cytotoxicity and T-Cell Proliferation is Enhanced by Avoidance Behavior.Brain," Behavior, and Immunity, 7, 144-153.

Mojani, M. S., Rahmat, A., Ramasam, R. \& Akhavan Hejazi, S. M. (2012). "Palm Tocotrienols and A-Tocopherol Attenuate
Inflammatory Biomarkers in Streptozotocin-Induced Diabetic Rats," Current Toics in Nutraceutical Research, 10, 117-122.

Moriguchi, S., Kobayashi, N. \& Kihino, Y. (1990). "High Dietary Intakes of Vitamin E and Cellular Immune Functions in Rats," Journal of Nutrition, 120, 1096-1102.

Pae, M., Meydani, S. N. \& Wu, D. (2012). "The Role of Nutrition in Enhancing Immunity in Aging," Aging and Disease 3, 91-129.

Peleg, A., Weerarathna, T., Mccarthy, J. \& Davis, T. (2007). "Common Infections in Diabetes: Pathogenesis, Management and Relationship to Glycaemic Control," Diabetes/Metabolism: Research and Reviews, 23, 3-13.

Pick Up, J. C. (2004). "Inflammation and Activated Innate Immunity in the Pathogenesis of Type 2 Diabetes," Diabetes Care, 27, 813-823.

Pradhan, A. D., Manson, J. E., Rifai, N., Buring, J. E. \& Ridker, P. M. (2001). “CReactive Protein, Interleukin 6, and Risk of Developing Type 2 Diabetes Mellitus," Journal of the American Medical Association, 286, 327-334.

Reiter, E., Jiang, Q. \& Christen, S. (2007). "Anti-Inflammatory Properties of A- and GTocopherol," Molecular Aspects of Medicine, 28, 668-691.

Ren, Z., Pae, M., Dao, M. C., Smith, D., Meydani, S. N. \& Wu, D. (2010). "Dietary Supplementation with Tocotrienols Enhances Immune Function in C57BL/6 Mice," Journal of Nutrition, 140, 13351341.

Rubinstein, R., Genaro, A., Motta, A., Cremaschi, G. \& Wald, M. (2008). "Impaired Immune Responses in StreptozotocinInduced Type I Diabetes in Mice, Involvement of High Glucose," Clinical \& Experimental Immunology, 154, 235-246.

Sena, C. M., Nunes, E., Gomes, A., Santos, M. S., Proenca, T., Martins, M. I. \& Seica, R. M. (2008). "Supplementation of Coenzyme 
Q10 and Alpha-Tocopherol Lowers Glycated Hemoglobin Level and Lipid Peroxidation in Pancreas of Diabetic Rats," Nutr. Res., 28, 113-121.

Singh, U., Devaraj, S. \& Jialal, I. (2005). "Vitamin E, Oxidative Stress, and Inflammation," Annual Review of Nutrition, 25, 151-174.

Singh, U. \& Jialal, I. (2004). "AntiInflammatory Effects of Alpha-Tocopherol," Ann.NY Acad.Sci., 1301, 195-203.

Skyler, J. S. (2011). "Immune Intervention for Type 1 Diabetes Mellitus," International Journal of Clinical Practice 65, 61-70.

Van Belle, T. L., Coppieters, K. T. \& Von Herath, M. G. (2011). "Type 1 Diabetes: Etiology, Immunology, and Therapeutic Strategies," Physiological Reviews, 91, 79 118.

Wilankar, C., Sharma, D., Checker, R., Khan, N. M., Patwardhan, R., Patil, A., Sandur, S. K. \& Devasagayam, T. P. A. (2011). "Role of Immunoregulatory Transcription Factors in Differential Immunomodulatory Effects of Tocotrienols," Free Radical Biology and Medicine, 51, 129-143.

Wright, J. R. E., Scism-Bacon, J. L. \& Andglass, L. C. (2006). "Oxidative Stress in Type 2 Diabete: The Role of Fasting and Postprandial Glycaemia," International Journal of Clinical Practice60, 308-314. 